\title{
Numerical Simulation of Heat Exchanger's Length's Effect in a Thermoacoustic Engine
}

\author{
Mohamed Zouhir Dar Ramdane ${ }^{1,2}$, Miloud Abidat ${ }^{2}$ and Mohamed Hamel $^{2}$ \\ 1. Institute of Maintenance and Industrial Security, University of Oran, BP1524, El M'Naouer, Oran 31000, Algérie \\ 2. Applied Mechanics Laboratory, USTO-MB, BP 1505 Oran El M'Naouer, Oran 31000, Algérie
}

\begin{abstract}
A numerical study of a standing-wave thermoacoustic engine is presented. The aim of this work is to study the effect of increasing the heat exchangers length on the acoustic power. The analysis of the flow and the prediction of the heat transfer are performed by solving the non linear unsteady Navier-Stocks equations using the finite volume method implemented in -ANSYS CFX- CFD code. The results show an increase in the limit cycle acoustic pressure and power as well as the specific work per cycle with the increase of heat exchangers length.
\end{abstract}

Key words: Thermoacoustic engine, CFD, heat exchanger, acoustic pressure.

\section{Nomenclature}

$\begin{array}{ll}P: & \text { Pressure (Pa) } \\ T: & \text { Temperature }(\mathrm{K}) \\ v: & \text { Specific volume }\left(\mathrm{m}^{3} \cdot \mathrm{kg}^{-1}\right) \\ u: & \text { Velocity }\left(\mathrm{m} \cdot \mathrm{s}^{-1}\right) \\ C p: & \text { Specific heat at constant pressure }\left(\mathrm{J} \cdot \mathrm{kg}^{-1} \cdot \mathrm{k}^{-1}\right) \\ L: & \text { Heat exchanger length }(\mathrm{m}) \\ t: & \text { Time (s) } \\ w: & \text { Specific work }\left(\mathrm{J} \cdot \mathrm{kg}^{-1}\right) \\ P u: & \text { Acoustic power }\left(\mathrm{W} \cdot \mathrm{m}^{-2}\right)\end{array}$

\section{Greek letters}

$\begin{array}{ll}\lambda: & \text { Thermal conductivity }\left(\mathrm{W} \cdot \mathrm{m}^{-1} \cdot \mathrm{k}^{-1}\right) \\ \rho: & \text { Density }\left(\mathrm{kg} \cdot \mathrm{m}^{-3}\right)\end{array}$

\section{Introduction}

Thermodynamic and fluid-dynamic processes in sound waves in gases can convert energy from one form to another. In these thermoacoustic processes, Swift [1] proclaimed in his study that high-temperature heat can be partially converted to acoustic power. According to research carried out by Penelet et al. [2], thermoacoustic systems give several

Corresponding author: Mohamed Zouhir Dar Ramdane, professor, research fields: fluid mechanics, heat transfer, thermodynamics, turbo-machinery, thermal solar energy and thermoacoustics. E-mail: darramdane77@yahoo.fr. advantages over conventional thermal fluids systems, their use have no effect on environment, their mechanical manufacture is relatively simple and a miniaturization of devices is achievable. Most of the literatures available on thermoacoustic are based on linear acoustic theory, see Backhaus and Swift [3], and Bastyr and Keolian [4]. Cheng et al. [5] declared that this posses a severe limitation to the actual system due to the intrinsic irreversibility of heat transfer and the nonlinear effects, vortex and acoustic streaming.

The first simulation was made by Cao et al. [6]. Other simulations made by Worlikar [7], Worlikar et al. [8], then by Besnoin [9] used a model with low Mach number to simulate the flow near a 2D plate. These simulations have demonstrated the existence of vortices at the ends of plate and allowed the addition of heat exchangers, Marx [10].

Using the numerical simulation code ANSYS CFX 4.4, Lycklama à Nijeholt et al. [11] have simulated a 2D mesh grids thermoacoustic engine, they found clear results on the nonlinear effect of the thermoacoustic system. They concluded that the ANSYS CFX CFD code prove to be a useful tool in the study of thermoacoustic phenomena that cannot be captured by one-dimensional linear codes. Our aim in 
this study is to carry out a numerical simulation of a standing-wave thermoacoustic engine startup, and to study the effect of increasing the length of heat exchangers on the acoustic power.

\section{Geometry and Grids Mesh}

The geometry considered is the same studied by Hireche et al. [12], Fig. 1, this geometry is described as an experimental device at LIMSI [13]. Total length of the device is $7.57 \mathrm{~m}$ and the stack is $150 \mathrm{~mm}$, its center is located at $826 \mathrm{~mm}$ from the left end of the tube. This consists of a stack of Stainless Steel plates with a thickness of $0.20 \mathrm{~mm}$, separated by a gap of $0.77 \mathrm{~mm}$, it is the same spacing between the stack and the heat exchangers. In this study four heat exchangers with different lengths $(7.87 \mathrm{~mm}, 15.74 \mathrm{~mm}, 23.61 \mathrm{~mm}$ and $31.48 \mathrm{~mm}$ ) are considered. A 2D mesh grid is built using hexahedral cells with a total cell count of approximately 500,000 elements cells (Fig. 2).

\section{Numerical Simulation}

A numerical simulation of a standing wave thermoacoustic engine was performed using the finite volume method, implemented in ANSYS CFX CFD code. The mathematical equations used to model fluid flow and heat transfer are the instantaneous equation of mass, momentum, energy conservation and the equation of state for ideal gas. The simulation domain consists of a fluid subdomain (Helium-Ideal gas) and a solid subdomain of the stack (stainless steel). The two heat exchangers are modeled as wall at constant temperature. Constant material properties of Helium and stainless steel are given in Table 1.

\subsection{Initial and Boundary Conditions}

An unsteady laminar compressible flow is assumed, the temperature of the heat sink and heat source are taken equal to $300 \mathrm{~K}$ and $360 \mathrm{~K}$, respectively. The non linear unsteady Navier-Stokes equations and the equation of total enthalpy are solved by ANSYS-CFX CFD code with a fixed time steps of $2.5 \times 10^{-5} \mathrm{~s}$ and the discretization for all variable is second-order.

The number of plates was reduced to one plate (Fig. 3). Periodic boundary conditions prescribed on the top and bottom of the computational domain. Symmetric boundary conditions prescribed on the north and south of the computational domain. The both ends of the TAE are closed by adiabatic. Initial value of velocity, pressure and temperature are given as an initial solution, zero velocity prescribed in the whole tube, the inner pressure of the tube is $P_{R}=1$ bar and the temperature gradient in the stack is linear. Pressure, temperature and velocity are monitored in several location of the computational domain.

\section{Results}

The results of the calculations are discussed in three parts. The first part deals with the aerothermodynamics

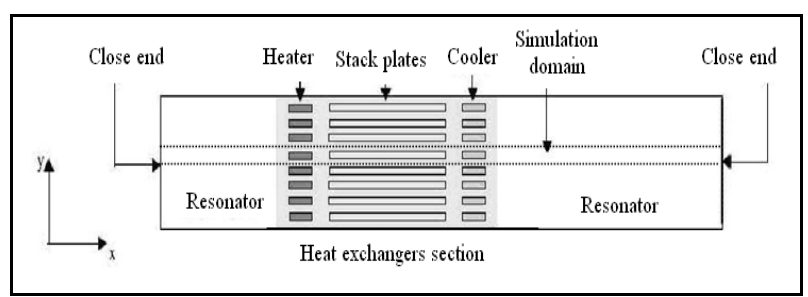

Fig. 1 Geometry and the simulation domain.

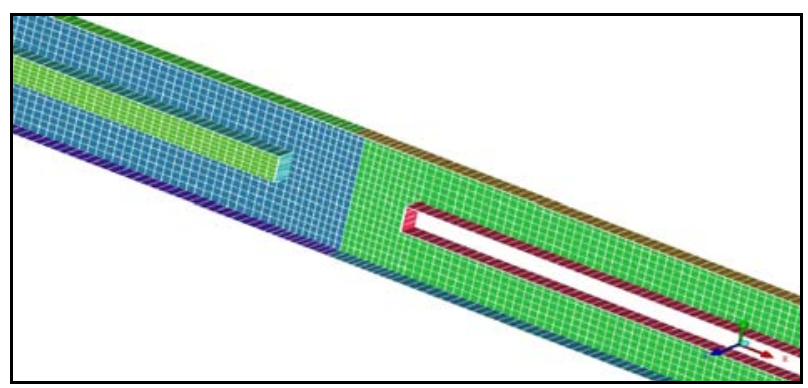

Fig. 2 The hexahedral mesh.

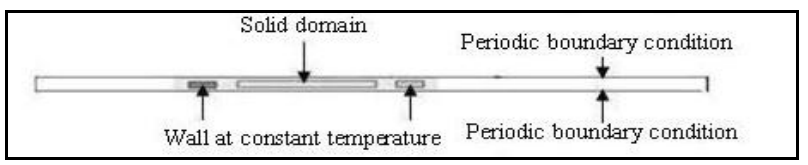

Fig. 3 Numerical representation of the geometry.

Table 1 Helium and stainless steel properties.

\begin{tabular}{llll}
\hline & $\lambda\left(\mathrm{W} \cdot \mathrm{m}^{-1} \cdot \mathrm{K}^{-1}\right)$ & $\boldsymbol{\rho}\left(\mathrm{kg} \cdot \mathrm{m}^{-3}\right)$ & $\boldsymbol{C} \boldsymbol{p}\left(\mathrm{J} \cdot \mathrm{kg}^{-1} \cdot \mathrm{K}^{-1}\right)$ \\
\hline Helium & $1.415 \times 10^{-4}$ & 0.1785 & 5,240 \\
Stainless Steel & 14.9 & 7,854 & 434 \\
\hline
\end{tabular}


results. The second part concerns the acoustic power of the TAE. The third part discusses the local specific work produced by TAE in one cycle.

\subsection{The Effect of Heat Exchangers Length on} Aerothermodynamics Parameters

Figs. 4a-4d show the transition of the oscillation from the initial state to the limit cycle by an acoustic self-excitation. The acoustic pressure increases until the limit cycle (saturation zone). The acoustic pressure $P_{a c}$ represents the dynamic pressure in the -ANSYS CFX CFD code and it is calculated according to the Eq. (1):

$$
P_{a c}=P_{a b s}-P_{R}
$$

where, $P_{a b s}$ is the absolute pressure and $P_{R}$ represents

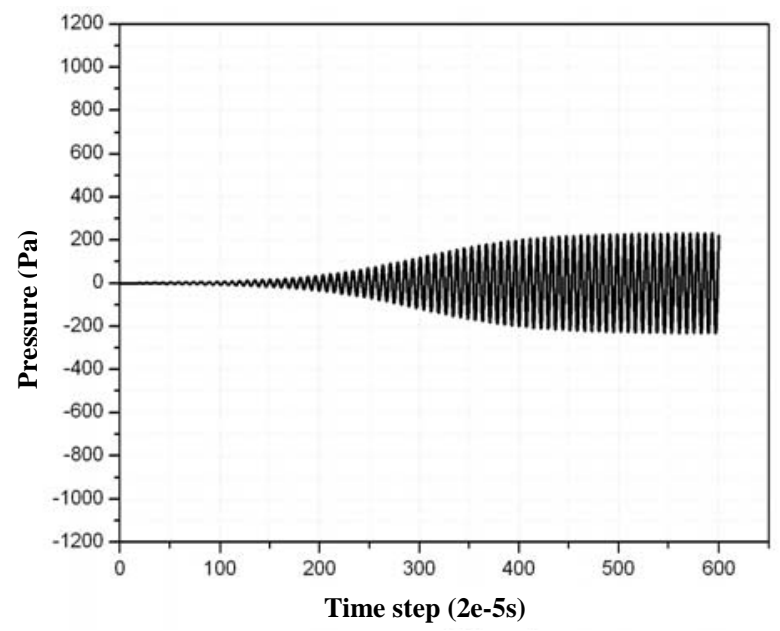

(a)

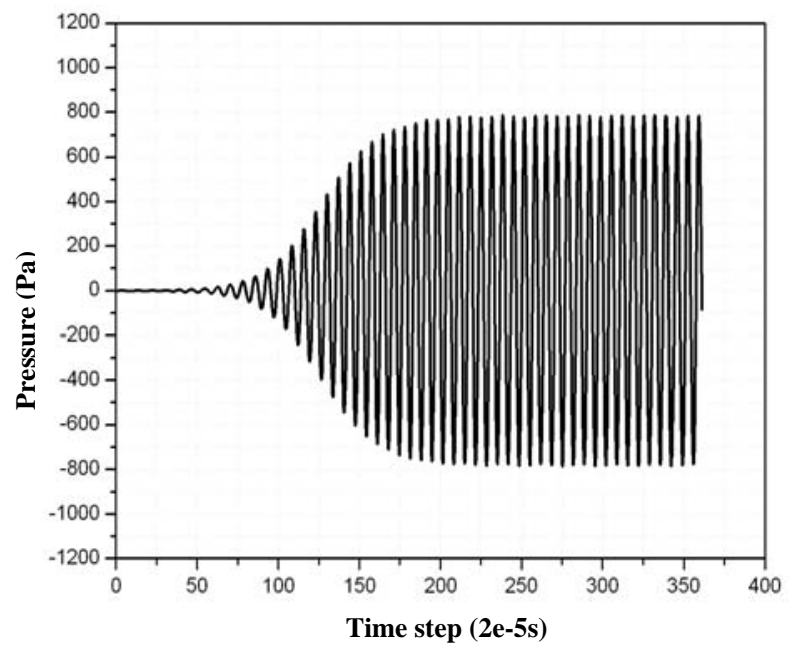

(c) the reference pressure ( $\left.P_{R}=1 \mathrm{bar}\right)$.

It is shown from Fig. 4a that the value of the limit cycle acoustic pressure for the ratio $\left(L / L_{R}\right)$ of one equals to $250 \mathrm{~Pa}$. It exceeds $600 \mathrm{~Pa}$ and $800 \mathrm{~Pa}$ for the ratio of 2 and 3 (Figs. 4b and 4c), and it reaches 1,100 Pa for the ratio of 4 (Fig. 4d). It is observed that the increase in acoustic pressure is associated with the increase of the length of the heat exchangers.

Increasing the length of the heat exchangers contributes to an augmentation of the heat exchange surface among the heat source and sink and the working gas. This rise is accompanied by an increase in the amount of the heat transfer in one cycle, this heat is transported to the stack and consequently more acoustic pressure is produced.

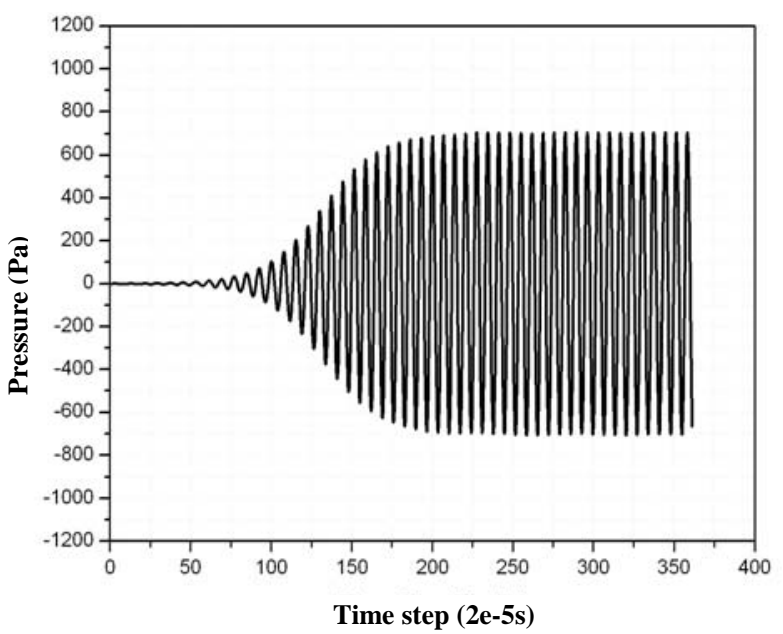

(b)

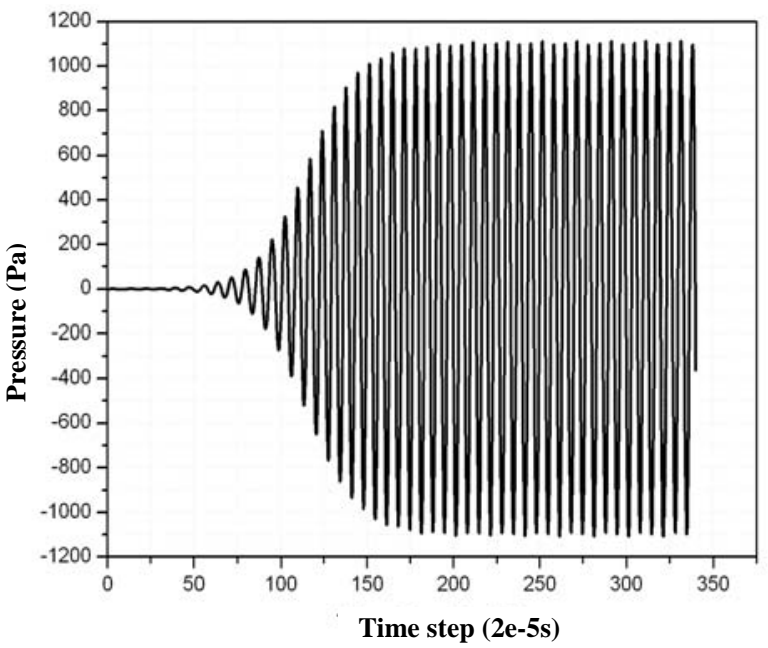

(d)

Fig. 4 Oscillation of the standing-wave thermoacoustic engine for the different length ratio $\left(L / L_{R}\right)$ of a working gas point position located at the stack center: (a) $L / L_{R}=1$; (b) $L / L_{R}=2$; (c) $L / L_{R}=3$; (d) $L / L_{R}=4$. 
The same observation is detected for the temperature and the axial velocity.

\subsection{The Effect of Heat Exchangers Length on the Acoustic Power}

The acoustic power $P_{u}$ is calculated from the CFD results for each time steps according to the Eq. (2):

$$
P u=P_{a c} \times u
$$

In this equation, the product of the acoustic pressure $P_{a c}$ and the velocity $u$ is averaged over all time steps during one cycle and integrated at $(y, z)$ cross section area located at the center of the stack.

The acoustic power for different length ratios is represented in Fig. 5. The value of the acoustic power increases from $62.9 \mathrm{Wm}^{-2}$ for the length ratio of one to $2,241.5 \mathrm{Wm}^{-2}$ for the length ratio of 4 . It is shown that there is a strong increase in the acoustic power while increasing the heat exchangers length. In fact, increasing the length of the heat exchangers is accompanied by a rise in the amount of heat rate added and rejected to the working gas in one cycle, and therefore, more acoustic power is produced.

\subsection{The Effect of Heat Exchangers Length on the} Specific Work

Fig. 6 shows the $P-v$ diagram of the TAE for different length ratios in a $(y, z)$ cross section area located at the center of the stack. The specific work exchanged during a cycle for different length ratios is calculated using Eq. (3):

$$
w_{c y}=\oint P_{a c} d v
$$

In this equation, the acoustic pressure $P_{a c}$ and the specific volume $v$ are integrated for all cycles and presented for the different length ratio in Fig. 6. A rise of the specific work with the increase of heat exchangers length is observed. This value is equal to $0.637 \mathrm{~J} \cdot \mathrm{kg}^{-1} \cdot \mathrm{m}^{-2}$ for the ratio of one, it passes through the values of $5.912 \mathrm{~J} \cdot \mathrm{kg}^{-1} \cdot \mathrm{m}^{-2}$ and $7.324 \mathrm{~J} \cdot \mathrm{kg}^{-1} \cdot \mathrm{m}^{-2}$ for the ratio of 2 and 3 and it reaches $14.819 \mathrm{~J} \cdot \mathrm{kg}^{-1} \cdot \mathrm{m}^{-2}$ for a ratio of 4 .

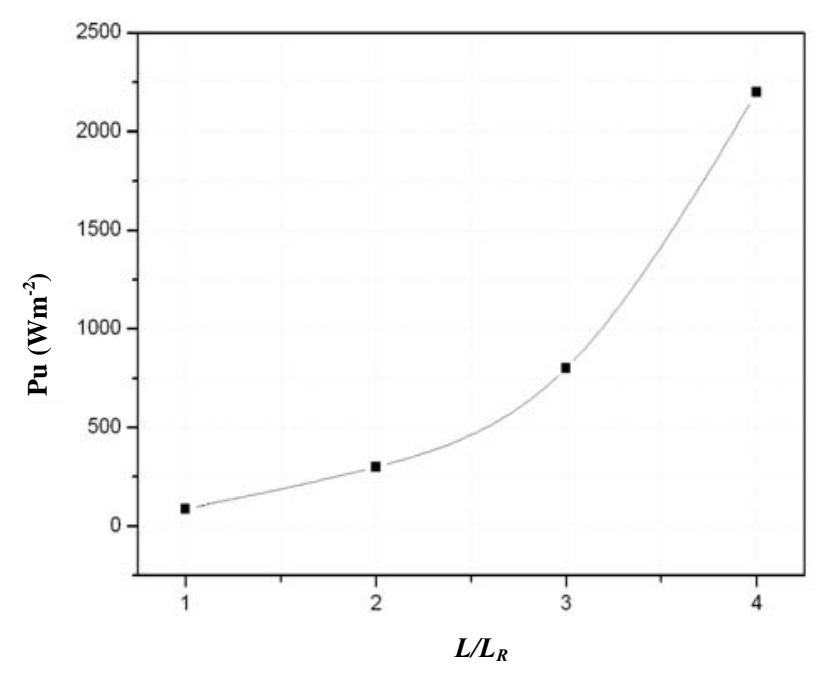

Fig. 5 The local acoustic power for different length ratio.

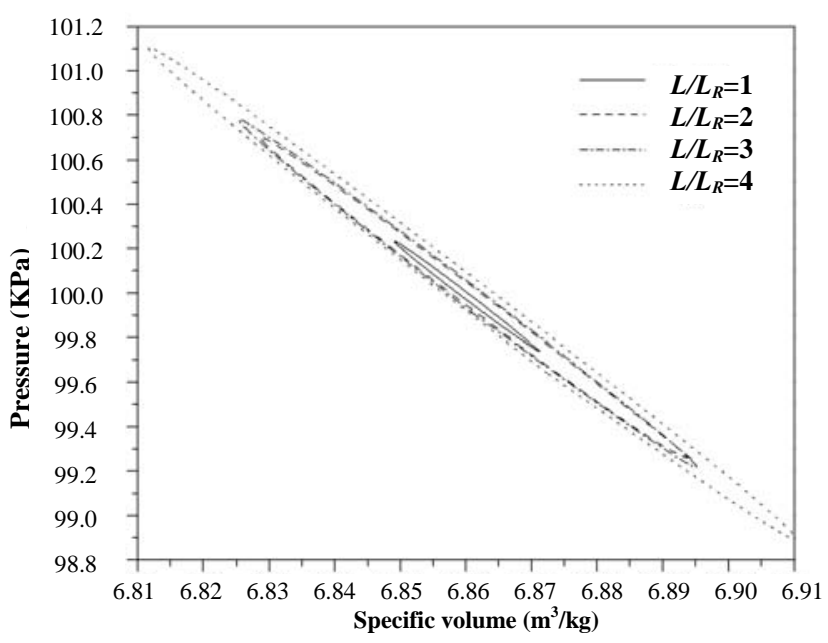

Fig. 6 The local $P$-v diagram cycles for the different length ratio.

It is shown that the increase in the specific work produced during one cycle is relative to the area including in the $P-v$ cycle. It is clearly shown that this area increase with the increase of the heat exchangers length and therefore more specific work is generated.

\section{Conclusions}

A numerical simulation of a standing wave thermoacoustic engine startup was performed. The effect of increasing the length of the heat exchangers on the acoustic pressure and power of the TAE was studied. This paper clearly shows that increasing length of the heat exchangers conduct to an increase in the aerothermodynamics parameters and the acoustic 
power of the TAE. This increase is observed for the specific work as well.

In order to advance the application of thermoacoustic systems, the CFD results should be validated against experimental data to obtain a design tool for the optimization of the thermoacoustic devices.

\section{References}

[1] Swift, G. W. 2002. A Unifying Perspective for Some Engines and Refrigerators. Sewickley PA: Acoustical Society of America Publications.

[2] Penelet, G., Gusev V., Lotton, P., and Bruneau, M. 2004. Journée SFT du Machines Thermiques Exotiques.

[3] Backhaus, S., and Swift, G. W. 2000. "A Thermoacoustic-Stirling Heat Engine: Detailed Study.” J. Acoust. Soc. Am. 107: 3148-66.

[4] Bastyr, K. J., and Keolian, R. M. 2003. "High-Frequency Thermoacoustic-Stirling Heat Engine Demonstration Device.” ARLO 4 (2): 37-40.

[5] Cheng, C. F., and Ngu, T. W. D. 2009. "CFD Study of Traveling Wave within a Piston-Less Striling Heat Engine.” Computational Fluid Dynamics 200841 (2): 813-4.
[6] Cao, N., Olson, J., Swift G. W., and Chen, S. 1996. “Energy Flux Density in a Thermoacoustic Couple." $J$. Acoust. Soc. Am. 99: 3456-64.

[7] Worlikar, A. 1997. "Numerical Simulation of Thermoacoustic Refrigerators.” Ph.D. thesis, Johns Hopkins University.

[8] Worlikar, A., and Knio, O. M. 1996. "Numerical Simulation of a Thermoacoustic Refrigerator. Part 1: Unsteady Adabiatic Flow around the Stack.” J. Comput. Phys. 127: 424-51.

[9] Besnoin, E. 2001. "Numerical Study of Thermoacoustic Heat Exchangers.” Ph.D. thesis, Johns Hopkins University.

[10] Marx, D. 2003. "Numerical Simulation of a Thermoacoustic Refrigerator.” Ph.D. thesis, Lyon Central School.

[11] Lycklama à Nijeholt, J. A., Tijani, M. E. H., and Spoelstra, S. 2005. "Simulation of a Traveling wave Thermoacoustic Engine Using Computational Fluid Dynamics.” J. Acoust. Soc. Am. 118: 2265-70.

[12] Hireche, O., Weisman, C., Baltean Carlés, D., Le Quéré, P., François, M. X., and Bauwens, L. 2010. "Numerical Model of a Thermoacoustic Engine.” Comptes rendus Mécanique 338: 18-23.

[13] Hireche, O. 2010. "Low Mach Number Analysis and Numerical Study of Thermoacoustic System.” Ph.D. thesis, University of Science and Technology of Oran. 